\title{
Cross Talk between Metabotropic and Ionotropic Glutamate Receptor-Mediated Signaling in Parallel Fiber-Induced Inositol 1,4,5-Trisphosphate Production in Cerebellar Purkinje Cells
}

\author{
Yohei Okubo, Sho Kakizawa, Kenzo Hirose, and Masamitsu Iino \\ Department of Pharmacology, Graduate School of Medicine, The University of Tokyo, Tokyo 113-0033, Japan
}

\begin{abstract}
In many excitatory glutamatergic synapses, both ionotropic glutamate receptors (iGluRs) and metabotropic glutamate receptors (mGluRs) are closely distributed on the postsynaptic membrane. However, the functional significance of the close distribution of the two types of glutamate receptors has not been fully clarified. In this study, we examined the functional interaction between iGluR and mGluR at parallel fiber $(\mathrm{PF}) \rightarrow$ Purkinje cell synapses in the generation of inositol 1,4,5-trisphosphate $\left(\mathrm{IP}_{3}\right)$, a key second messenger that regulates many important cellular functions. We visualized local $\mathrm{IP}_{3}$ dynamics in Purkinje cells using the green fluorescent proteintagged pleckstrin homology domain (GFP-PHD) as a fluorescent $\mathrm{IP}_{3}$ probe. Purkinje cells were transduced with Sindbis virus encoding GFP-PHD and imaged with a two-photon laser scanning microscope. Translocation of GFP-PHD from the plasma membrane to the cytoplasm attributable to an increase in $\mathrm{IP}_{3}$ concentration was observed on PF stimulation in fine dendrites of Purkinje cells. Surprisingly, this PF-induced $\mathrm{IP}_{3}$ production was blocked not only by the group I mGluR antagonist but also by the AMPA receptor (AMPAR) antagonist. The PF-induced IP ${ }_{3}$ production was blocked by either the inhibition of G-protein activation by GDP- $\beta$ S or intracellular $\mathrm{Ca}^{2+}$ buffering by BAPTA. These results show that $\mathrm{IP}_{3}$ production is mediated cooperatively by group I mGluR and AMPAR through G-protein activation and $\mathrm{Ca}^{2+}$ influx at $\mathrm{PF} \rightarrow$ Purkinje cell synapses, identifying the robust cross talk between iGluR and mGluR for the generation of IP ${ }_{3}$ signals.
\end{abstract}

Key words: inositol 1,4,5-trisphosphate; calcium; metabotropic glutamate receptor; AMPA receptor; parallel fiber; Purkinje cells

\section{Introduction}

Close distribution of ionotropic glutamate receptors (iGluRs) and metabotropic glutamate receptors (mGluRs) is often observed on the postsynaptic membrane of excitatory glutamatergic synapses in the CNS (Takumi et al., 1999). Cerebellar Purkinje cells receive numerous excitatory inputs from parallel fibers $(\mathrm{PFs})$. On the postsynaptic membrane of the $\mathrm{PF} \rightarrow$ Purkinje cell synapses, iGluRs [AMPA receptors (AMPARs)] are concentrated at the postsynaptic densities, whereas mGluRs (mGluR1s) are distributed at the periphery of the postsynaptic densities (Baude et al., 1993; Nusser et al., 1994). It has been considered that the two types of glutamate receptors send separate downstream signals. Whereas AMPAR generates EPSCs to depolarize the postsynaptic membrane, group I mGluRs including mGluR1 couple to phospholipase C (PLC) via the heterotrimeric G-protein to hydrolyze phosphatidylinositol 4,5-bisphosphate $\left(\mathrm{PIP}_{2}\right)$, generating inositol 1,4,5-trisphosphate $\left(\mathrm{IP}_{3}\right)$ and diacyl-

\footnotetext{
Received May 12, 2004; revised Aug. 3, 2004; accepted Aug. 3, 2004

This work was supported by grants from the Ministry of Education, Culture, Sports, Science and Technology of Japan.

Correspondence should be addressed to Masamitsu lino, Department of Pharmacology, Graduate School of Medicine, The University of Tokyo, 7-3-1 Hongo Bunkyo-ku, Tokyo 113-0033, Japan. E-mail: iino@m.u-tokyo.ac.jp. DOI:10.1523/JNEUROSCI.1829-04.2004

Copyright $\odot 2004$ Society for Neuroscience $\quad$ 0270-6474/04/249513-08\$15.00/0
}

glycerol (Masu et al., 1991; Taylor et al., 1991; Abe et al., 1992; Aramori and Nakanishi, 1992). However, recent results showed that both AMPAR and mGluR collaborate in the generation of the $\mathrm{Ca}^{2+}$ signal and EPSC at $\mathrm{PF} \rightarrow$ Purkinje cell synapses (Eilers et al., 1995; Finch and Augustine, 1998; Takechi et al., 1998; Tempia et al., 1998; Kim et al., 2003). On the other hand, our recent finding that the activation of AMPAR induces $\mathrm{IP}_{3}$ production through $\mathrm{Ca}^{2+}$ influx in Purkinje cells (Okubo et al., 2001) raised the possibility that not only mGluR but also AMPAR participates in the generation of an $\mathrm{IP}_{3}$ signal at $\mathrm{PF} \rightarrow$ Purkinje cell synapses. However, this possibility has not been tested at the synaptic sites because of the lack of technique to measure $\mathrm{IP}_{3}$ dynamics with a sufficient spatiotemporal resolution.

We have shown that intracellular $\mathrm{IP}_{3}$ dynamics can be visualized within intact cells using the green fluorescent protein-tagged pleckstrin homology domain of PLC- $\delta 1$ (GFP-PHD) (Hirose et al., 1999). GFP-PHD binds to $\mathrm{PIP}_{2}$ within the plasma membrane and translocates to the cytoplasm on an increase in the concentration of $\mathrm{IP}_{3}$ because of its $\sim 20$-fold higher affinity for $\mathrm{IP}_{3}$ than for $\mathrm{PIP}_{2}$. Therefore, by imaging the translocation of GFP-PHD, we can measure the change in intracellular $\mathrm{IP}_{3}$ concentration. We have also shown that GFP-PHD can be used to measure intracellular $\mathrm{IP}_{3}$ dynamics in single Purkinje cells (Okubo et al., 2001). In this report, the $\mathrm{IP}_{3}$ imaging method was combined with a high- 
spatiotemporal resolution imaging technique using a twophoton laser scanning microscope (TPLSM) (Denk and Svoboda, 1997) to visualize the local $\mathrm{IP}_{3}$ dynamics in response to $\mathrm{PF}$ inputs in Purkinje cells within cerebellar slices. This imaging technique now allows us to visualize the local $\mathrm{IP}_{3}$ dynamics on PF inputs in the fine dendrites of Purkinje cells. Unexpectedly, $\mathrm{IP}_{3}$ production on PF stimulation was found to be dependent on the simultaneous activation of group I mGluR and AMPAR. In addition, this $\mathrm{PF}$-induced $\mathrm{IP}_{3}$ production was blocked by the inhibition of the G-protein function and by buffering of intracellular $\mathrm{Ca}^{2+}$ concentration. These results show that the PF-induced $\mathrm{IP}_{3}$ production is mediated cooperatively by group I mGluR and AMPAR through G-protein activation and $\mathrm{Ca}^{2+}$ influx in Purkinje cells.

\section{Materials and Methods}

Sindbis viruses. The enhanced GFP (EGFP) gene in pIRES2-EGFP (Clontech, Palo Alto, CA) was replaced by the cDNA encoding GFP-PHD (Hirose et al., 1999) to generate the cDNA encoding internal ribosomal entry site (IRES)-GFP-PHD. The cDNA encoding IRES-GFP-PHD was cloned into pSinRep5 (Invitrogen, Carlsbad, CA). This vector was then used as the template for in vitro transcription using SP6 RNA polymerase (Invitrogen or Ambion, Austin, TX). The RNA transcript and the helper RNA from a DH(26S) cDNA template (Invitrogen) were cotransfected into baby hamster kidney cells by electroporation. Twenty-four hours after transfection, the culture medium was harvested because this contained the infectious particles of Sindbis virus (SIN)-IRES-GFP-PHD. IRES-dependent translations were shown to be less efficient than capdependent translations (Ehrengruber et al., 1999; Okubo et al., 2001) and were used here to avoid the overexpression of GFP-PHD. Rat $\mathrm{IP}_{3}$ 5-phosphatase (Hirose et al., 1999) was cloned into pSinRep5 with IRESGFP-PHD to generate the cDNA encoding 5-phosphatase [wild type (WT)]-IRES-GFP-PHD. Arginine 343 of $\mathrm{IP}_{3}$ 5-phosphatase was mutated to alanine by the PCR technique using a mutated primer. The cDNA fragment including the mutated site was used to replace the corresponding site in 5-phosphatase (WT) to generate the cDNA of 5-phosphatase (R343A)-IRES-GFP-PHD cloned into pSinRep5. The infectious particles were acquired by the same procedure described above.

Infection of Purkinje cells and preparation of cerebellar slices. C57BL/6 mice [postnatal day 18 (P18)-P29] were deeply anesthetized with pentobarbital, and the surface of cerebellar lobule 6 beside the midline was exposed by removing the cranium and the dura. The tips of glass pipettes were backfilled with virus in the medium $(\sim 0.5 \mu \mathrm{l})$. Glass pipettes were then inserted into the cerebellum so that the tips of the pipettes were placed at the molecular layer of cerebellar lobule 6 facing lobule 4/5. The virus-containing medium was delivered over $5 \mathrm{~min}$ by air pressure applied through the microsyringe. The glass pipettes were then left in place for $5 \mathrm{~min}$ to prevent virus leakage. Twenty to twenty-six hours after the injection, parasagittal cerebellar slices ( $250 \mu \mathrm{m}$ thickness) were prepared as described previously (Edwards et al., 1989; Aiba et al., 1994; Kakizawa et al., 2000). Slices were incubated in a holding chamber containing artificial CSF (ACSF) bubbled with $95 \% \mathrm{O}_{2}$ and $5 \% \mathrm{CO}_{2}$ at $35^{\circ} \mathrm{C}$ for $1 \mathrm{hr}$ and then returned to $23^{\circ} \mathrm{C}$ before recording. ACSF for slicing and incubation contained (in mM): $125 \mathrm{NaCl}, 2.5 \mathrm{KCl}, 2 \mathrm{CaCl}_{2}, 1 \mathrm{MgSO}_{4}, 1.25$ $\mathrm{NaH}_{2} \mathrm{PO}_{4}, 26 \mathrm{NaHCO}_{3}$, and 20 glucose.

Electrophysiology. For recording, slices were transferred to a recording chamber that was continuously perfused with ACSF bubbled with $95 \%$ $\mathrm{O}_{2}$ and $5 \% \mathrm{CO}_{2}$ and containing $10 \mu \mathrm{M}$ bicuculline to block spontaneous IPSCs. Whole-cell recordings were made from Purkinje cells using an upright microscope (BX61WI; Olympus Optical, Tokyo, Japan). The resistances of patch pipettes were 2-5 M $\Omega$ when filled with an intracellular solution containing (in $\mathrm{mm}$ ): $148 \mathrm{~K}$ gluconate, $2 \mathrm{NaCl}, 4 \mathrm{MgCl}_{2}, 4$ ATP (Na salt), 0.4 GTP (Na salt), and 10 HEPES, pH 7.3 (adjusted with $\mathrm{KOH})$. An intracellular solution also contained $0.2 \mathrm{~mm}$ X-rhod-1 (Molecular Probes, Eugene, OR) or $0.2 \mathrm{~mm}$ Calcium Green-5N (Molecular Probes). EPSCs were recorded with an EPC-9 patch-clamp amplifier (HEKA Elektronik, Lambrecht/Pfalz, Germany) using the voltage-clamp mode. The signals were filtered at $2 \mathrm{kHz}$ and digitized at $10 \mathrm{kHz}$. The on-line data acquisition and off-line analysis of data were performed using PULSE software (HEKA). A stimulation pipette (3-7 $\mu \mathrm{m}$ tip diameter) was filled with ACSF and placed near the site where the PF-induced response was to be imaged (within $15 \mu \mathrm{m}$ in the lateral direction and $10-50 \mu \mathrm{m}$ above in the vertical direction) to apply square pulses for the focal stimulation of PFs (duration, $0.1 \mathrm{msec}$; amplitude, 4-36 V). Lowamplitude $\mathrm{Ca}^{2+}$ transients attributable to direct stimulation of Purkinje cells were observed when high-frequency stimulus pulses (10 at $50 \mathrm{~Hz}$ ) with large amplitudes (25-36 V) were applied via the stimulation electrode placed very close to the dendrites $(10-15 \mu \mathrm{m}$ above, 12 runs from 12 cells). Such a stimulation configuration was avoided in our experiments. Experiments were performed at room temperature $\left(23-25^{\circ} \mathrm{C}\right)$.

Imaging. Imaging was performed with a custom-made TPLSM (Nemoto et al., 2001; Takahashi et al., 2002) consisting of an upright microscope (BX61WI; Olympus Optical) equipped with a scanning unit (FV300; Olympus Optical) and a Ti:sapphire laser providing a modelocked femtosecond-pulse laser (Tsunami; Spectra-Physics, Mountain View, CA). Purkinje cells that expressed a sufficient amount of GFPPHD were selected based on morphological criteria (large, round soma and prominent dendritic arbor) and then viewed under a water immersion objective ( $40 \times$; numerical aperture, 0.80 ). The distal dendrite that showed a clear membranous distribution of GFP-PHD was selected for imaging. For the imaging of $\mathrm{Ca}^{2+}$ transients, X-rhod-1 or Calcium Green-5N was applied to Purkinje cells through the patch pipette. Imaging was started at least $20 \mathrm{~min}$ after the establishment of the whole-cell configuration to allow the diffusion of X-rhod-1 or Calcium Green-5N. Both GFP-PHD and X-rhod-1 were excited at $900 \mathrm{~nm}$ (pulse width, $70-100 \mathrm{fsec}$ ). Calcium Green-5N was excited at $810 \mathrm{~nm}$ (pulse width, $70-100 \mathrm{fsec}$ ). Emitted fluorescence was filtered using an infrared ray cutting filter and then separated by a $565 \mathrm{~nm}$ dichroic mirror (DM565; Olympus Optical). A 495-540 nm barrier filter (BA495-540; Olympus Optical) was placed in the shorter-wavelength pathway to isolate GFP or Calcium Green-5N fluorescence and, a $590 \mathrm{~nm}$ long-pass filter (BA590; Olympus Optical) was placed in the longer-wavelength pathway to isolate X-rhod-1 fluorescence. External photomultiplier tubes (Hamamatsu Photonics, Hamamatsu, Japan) were used to detect fluorescence. Data were acquired using FluoView 4.2 software (Olympus Optical). Stimulus-induced changes in fluorescence were recorded using the line scan mode with a $5 \mathrm{msec}$ time resolution. Fluorescence signals were corrected for background fluorescence by measuring a nonfluorescent area.

Drugs. (S)-4-Carboxyphenylglycine (4-CPG), 6-nitro-7-sulfamoylbenzo[f] quinoxaline-2,3-dione (NBQX; disodium salt), and bicuculline were obtained from Tocris Cookson (Ballwin, MO); GDP- $\beta$ S was from Sigma (St. Louis, MO); and BAPTA was from Dojindo (Kumamoto, Japan). 4-CPG, NBQX, and bicuculline were dissolved in ACSF and administered to the cells through the perfusion system of the recording chamber. GDP- $\beta$ S and BAPTA were dissolved in the intracellular solution and introduced into the cytoplasm through the patch pipette. For the intracellular delivery of BAPTA, the intracellular solution was used, which contained (in mM): $114 \mathrm{~K}$ gluconate, $2 \mathrm{NaCl}, 4 \mathrm{MgCl}_{2}, 6 \mathrm{CaCl}_{2}, 4$ ATP (Na salt), 0.4 GTP (Na salt), 10 HEPES, 20 BAPTA, and 0.2 X-rhod-1, pH 7.3 (adjusted with $\mathrm{KOH}$ ).

\section{Results}

Sindbis-mediated expression of GFP-PHD in Purkinje cells in cerebellar slices

We expressed GFP-PHD in Purkinje cells using Sindbis virus carrying a gene encoding GFP-PHD (SIN-IRES-GFP-PHD). Twenty to twenty-six hours after the injection of infectious particles of the Sindbis virus into the cerebellum of P18-P29 mice, acute cerebellar slices were prepared. Figure $1 A$ shows a Purkinje cell transduced with SIN-IRES-GFP-PHD in the cerebellar slice imaged using TPLSM. GFP-PHD was localized mainly in the narrow region of cell borders corresponding to the plasma membrane. This is in accordance with its affinity for $\mathrm{PIP}_{2}$ on the plasma membrane. 
A
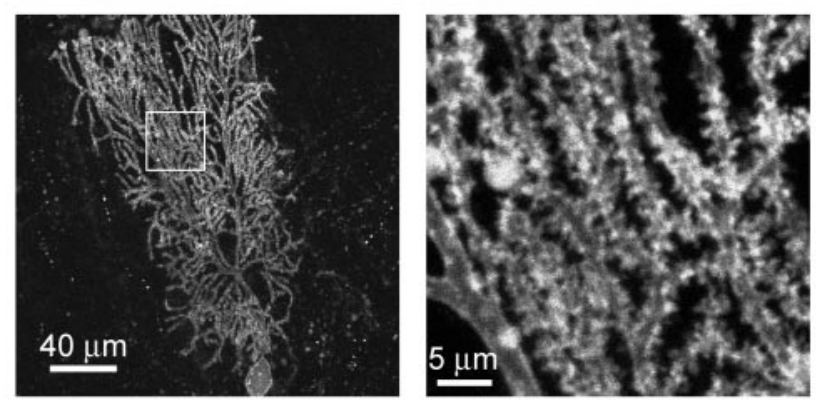

B
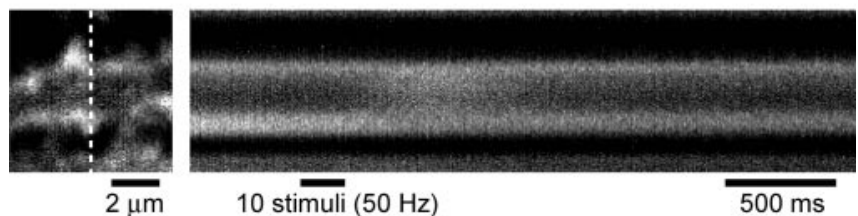

C

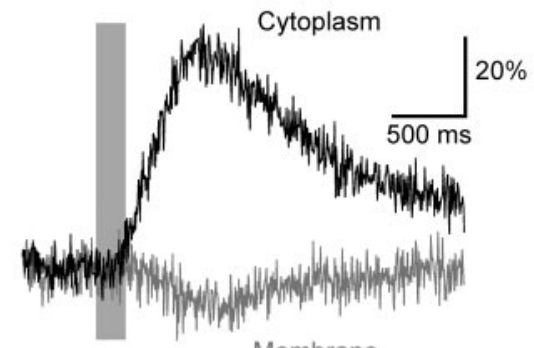

Membrane

Figure 1. PF-induced translocation of GFP-PHD in Purkinje cells. A, Purkinje cells infected with SIN-IRES-GFP-PHD were imaged with TPLSM. GFP-PHD was excited at $900 \mathrm{~nm}$. The right panel shows the high-magnification image of a part of the dendrite in the left panel (indicated by the white box). Twenty images acquired at $2 \mu \mathrm{m}$ intervals were projected onto a plane for the left panel, and seven images were projected for the right panel. Fragments of adjacent cells made during the slicing procedure are seen as small dots near and over the Purkinje cells. $B$, Representative line scan image during PF stimulation. The left panel shows the fluorescence image of a Purkinje cell dendrite. The dashed line indicates the location of time-lapse line scanning. The right panel shows a line scan image on repetitive PF stimulations (10 stimuli at 50 $\mathrm{Hz}$, indicated by the horizontal bar). C, Averaged time courses (14 runs from 14 cells) of fractional changes in the fluorescence intensity $\left(\Delta F / F_{0}\right.$, normalized by the average of 10 line scans taken immediately before PF stimulation) in the cytoplasm and the plasma membrane. PF stimulation (10 stimuli at $50 \mathrm{~Hz}$ ) is indicated by the gray bar. Averaged time courses of the reduction of fluorescence intensity attributable to photobleaching were subtracted from the traces.

\section{PF-induced translocation of GFP-PHD}

Repetitive PF inputs were reported to induce the release of $\mathrm{Ca}^{2+}$ via $\mathrm{IP}_{3}$ receptor $\left(\mathrm{IP}_{3} \mathrm{R}\right)$ through the activation of $m G l u R$ in Purkinje cells (Finch and Augustine, 1998; Takechi et al., 1998). To analyze the local $\mathrm{IP}_{3}$ dynamics that underlies the PF-induced $\mathrm{Ca}^{2+}$ release, we imaged changes in the localization of GFP-PHD in response to PF stimulation (Fig. $1 B$ ). The bright peripheral region was defined as the plasma membrane, and the region flanked by the peripheral regions was defined as the cytoplasm. The clear membranous localization of GFP-PHD was observed in fine dendrites within the distal dendritic region (Fig. $1 B$ ). The stimulation pipette was placed on top of a cerebellar slice to stimulate the PFs that innervate the dendrite of interest (see Materials and Methods). When fast line scan image acquisition was performed to include the cytoplasm and the plasma membrane of the fine dendrites, a marked increase in the fluorescence intensity was observed within the cytoplasm in response to the repetitive stimulations of PFs with a physiologically relevant (Merrill et al., 1978; Chadderton et al., 2004) number and frequency (10 stimuli at $50 \mathrm{~Hz})($ Fig. $1 \mathrm{~B})$. Averaged time course of fractional changes in fluorescence intensity $\left(\Delta F / F_{0}\right)$ on PF stimulation showed a transient increase in $\Delta F / F_{0}$ in the cytoplasm and a concomitant decrease in the plasma membrane (Fig. $1 C$ ). The changes in the fluorescence intensity indicate the translocation of GFP-PHD from the plasma membrane to the cytoplasm (Hirose et al., 1999; Okubo et al., 2001). The difference in the peak amplitude of PF-induced $\Delta F / F_{0}$ transients between the cytoplasm and the plasma membrane is mainly attributable to a high surface-tovolume ratio in fine dendrites (i.e., the thinner the dendrites, the greater the cytoplasmic increase in the concentration of GFPPHD for the same amount of translocation from the membrane to the cytoplasm). It is also possible that the definition of the plasma membrane region included the adjacent cytoplasmic region to a small extent, resulting in a slight exaggeration of the difference. Because neuronal activity is known to cause changes in intracellular pH (Chesler and Kaila, 1992) that could affect the fluorescence intensity of GFP (Kneen et al., 1998) and thus the GFP-PHD signal, we evaluated PF stimulation-induced changes in GFP fluorescence. PF stimulation (10 stimuli at $50 \mathrm{~Hz}$ ) was applied to Purkinje cells transduced with Sindbis virus encoding GFP (Okubo et al., 2001). Only a slight reduction in $\Delta F / F_{0}$ was observed $(-0.018 \pm 0.004$, mean of peak change \pm SEM, during $1 \mathrm{sec}$ from onset of stimulation, 10 runs from 10 cells), indicating that there is very little effect of PF-induced $\mathrm{pH}$ changes on GFPPHD signals.

\section{PF-induced GFP-PHD translocation reflects $\mathrm{IP}_{3}$ dynamics}

To confirm that PF-induced GFP-PHD translocation depends on the increase in the intracellular $\mathrm{IP}_{3}$ concentration, we examined the effect of $\mathrm{IP}_{3} 5$-phosphatase overexpression (Fig. 2). Because $\mathrm{IP}_{3}$ 5-phosphatase hydrolyzes $\mathrm{IP}_{3}$ but not $\mathrm{PIP}_{2}$ (Majerus, 1992; Laxminarayan et al., 1994), the overexpression of $\mathrm{IP}_{3}$ 5-phosphatase should specifically inhibit an increase in cytoplasmic $\mathrm{IP}_{3}$ concentration. We therefore constructed a Sindbis virus carrying the gene encoding $\mathrm{IP}_{3}$ 5-phosphatase followed by GFPPHD under the control of the internal ribosomal entry site [SIN5-ppase (WT)-IRES-GFP-PHD] to coexpress $\mathrm{IP}_{3}$ 5-phosphatase and GFP-PHD. In addition, we also generated a similar virus in which arginine 343 of the $\mathrm{IP}_{3}$ 5-phosphatase was replaced by alanine [SIN-5-ppase (R343A)-IRES-GFP-PHD]. This mutation (R343A) resulted in the loss of enzymatic activity (Communi et al., 1996) and was used here as a negative control. As shown in Figure 2, most of the PF-induced GFP-PHD translocation was blocked in the $\mathrm{IP}_{3} 5$-phosphatase (WT)-expressing cells, whereas the PF-induced translocation was observed in cells expressing the R343A-mutant $\mathrm{IP}_{3}$ 5-phosphatase. These results show the requirement of the increase in $\mathrm{IP}_{3}$ concentration for the GFP-PHD translocation during PF stimulation, indicating that PF-induced GFP-PHD translocation reports the intracellular $\mathrm{IP}_{3}$ dynamics.

We observed a delay in the appearance of GFP-PHD translocation after PF stimulation. The duration of delay time shows a good agreement with the lag time observed in the PF-induced $\mathrm{Ca}^{2+}$ release via $\mathrm{IP}_{3} \mathrm{R}$ in previous reports and in our results (Finch and Augustine, 1998; Takechi et al., 1998) (Figs. 3A, 4A). The enzymatic reaction time for $\mathrm{IP}_{3}$ generation after glutamate binding to the mGluR seems to account for most of the delay 
A
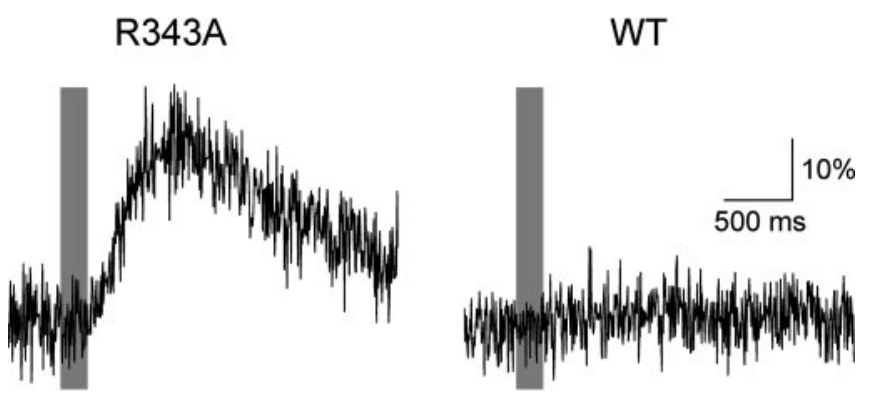

A

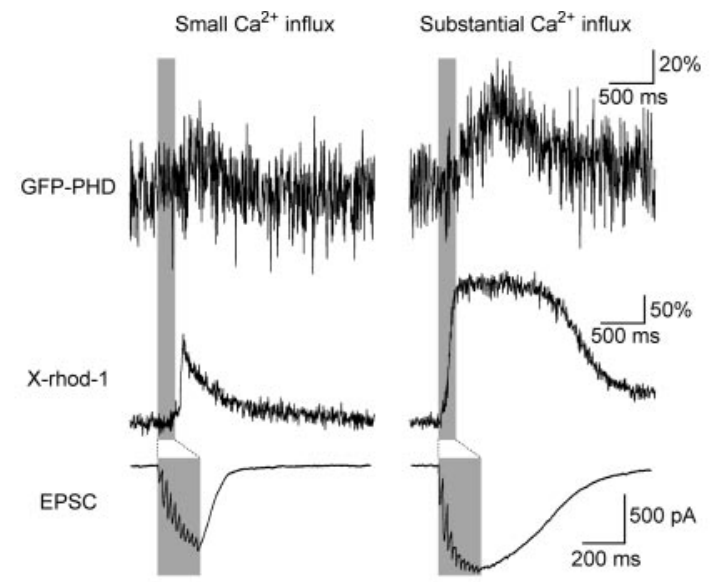

B

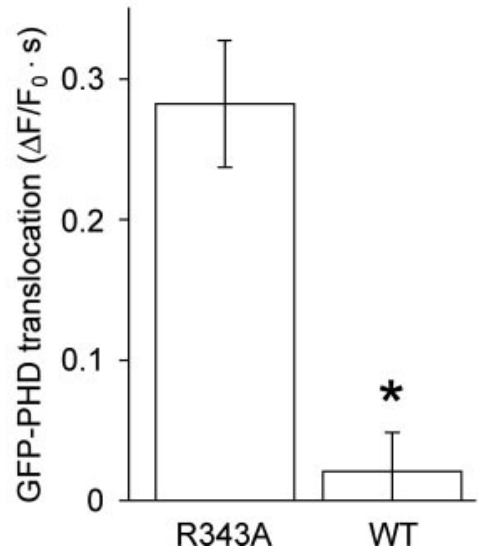

Figure 2. Increase in $\mathbb{P}_{3}$ concentration is necessary for PF-induced GFP-PHD translocation. $A$, PF-induced GFP-PHD translocation in the R343A mutant IP ${ }_{3}$-phosphatase-expressing cell (left trace) and the wild-type $\mathbb{I}_{3} 5$-phosphatase-expressing cell (right trace). Averaged time courses of $\Delta F / F_{0}$ (8 runs from 8 cells in each experiment) within the cytoplasm during PF stimulation (10 stimuli at $50 \mathrm{~Hz}$, indicated by the gray bar) are shown. $B$, Time integrals of $\Delta F / F_{0}$ (measured during $1.5 \mathrm{sec}$ from the onset of PF stimulation) in the traces shown in $A$ (mean \pm SEM). PF-induced GFP-PHD translocation was blocked in the wild-type $\mathbb{I P}_{3} 5$-phosphataseexpressing cells compared with the R343A control cells. ${ }^{*} p<0.001$ (Student's unpaired $t$ test).

time, although the finite dissociation rate constant $\left(>5 \mathrm{sec}^{-1}\right)$ of GFP-PHD from PIP $_{2}$ (Hirose et al., 1999) may account for a fraction of the observed delay.

Simultaneous imaging of $\mathrm{IP}_{3}$ production and $\mathrm{Ca}^{2+}$ transients Simultaneous imaging of $\mathrm{IP}_{3}$ and $\mathrm{Ca}^{2+}$ transients offers valuable information for understanding the relationship between $\mathrm{IP}_{3}$ and $\mathrm{Ca}^{2+}$ signaling (Hirose et al., 1999) and is indispensable for the evaluation of the involvement of AMPAR in PF-induced $\mathrm{IP}_{3}$ production via $\mathrm{Ca}^{2+}$ influx. We applied the whole-cell patch-clamp method to GFP-PHD-expressing Purkinje cells and introduced into the cells a fluorescent $\mathrm{Ca}^{2+}$ indicator, $\mathrm{X}$-rhod-1, through the patch pipette. Both GFP-PHD and X-rhod-1 were excited at 900 $\mathrm{nm}$. Because X-rhod-1 emits a red fluorescence, its signal can be resolved from the fluorescence of GFP-PHD. This enabled us to simultaneously measure the concentrations of $\mathrm{Ca}^{2+}$ and $\mathrm{IP}_{3}$, as well as EPSC, on PF stimulation (Fig. $3 A$ ). We voltage clamped Purkinje cells to eliminate the possible $\mathrm{Ca}^{2+}$ influx via voltagegated $\mathrm{Ca}^{2+}$ channels triggered by somatic action potentials (Denk et al., 1995) and to evaluate the local involvement of AMPAR in PF-induced $\mathrm{IP}_{3}$ production. It has been reported that
B
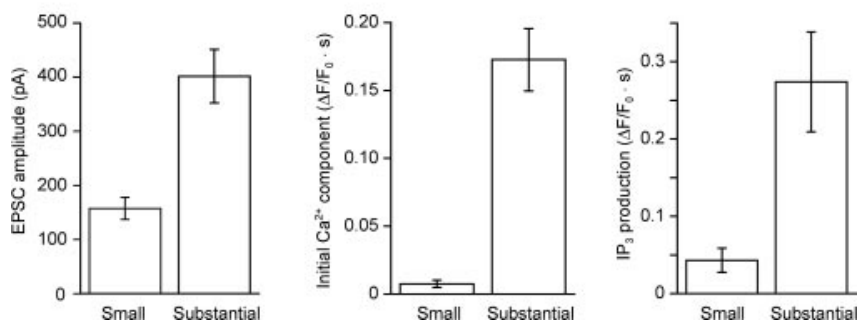

Figure 3. Simultaneous measurement of $\mathrm{IP}_{3}$ production, $\mathrm{Ca}^{2+}$ transients and EPSC. A, Representative traces of $\mathrm{IP}_{3}$ production (top traces), $\mathrm{Ca}^{2+}$ transient (middle traces), and EPSC (bottom traces) during PF stimulation ( 10 stimuli at $50 \mathrm{~Hz}$, indicated by the gray bar). These three measurements were performed simultaneously. PF stimulation with a minimal intensity for inducing a substantial delayed $\mathrm{Ca}^{2+}$ transient (left traces) was followed by PF stimulation at a higher intensity for inducing a substantial initial component in the $\mathrm{Ca}^{2+}$ transient (right traces) in the same preparations. Stimulus artifacts in the EPSC traces were omitted for clarity in this and the following figures. $B$, Time integrals of $I P_{3}$ production (during 1.5 sec from the onset of PF stimulation; right graph), time integrals of the initial component of $\mathrm{Ca}^{2+}$ transients (during $200 \mathrm{msec}$ from the onset of PF stimulation; middle graph), and amplitudes of EPSC evoked by the first stimulus pulse of 10 stimuli at $50 \mathrm{~Hz}$ (left graph) are shown (mean \pm SEM). Results from seven experiments are compiled.

AMPAR-triggered $\mathrm{Ca}^{2+}$ influx via voltage-gated $\mathrm{Ca}^{2+}$ channels could be observed under voltage clamping because of insufficient clamping in dendritic regions of Purkinje cells (Denk et al., 1995; Eilers et al., 1995; Finch and Augustine, 1998; Takechi et al., 1998).

It was reported that the $\mathrm{Ca}^{2+}$ transient induced by a brief train of PF inputs has two distinct components. The initial component coincides with the EPSC and depends on AMPAR-triggered $\mathrm{Ca}^{2+}$ influx via voltage-gated $\mathrm{Ca}^{2+}$ channels (Denk et al., 1995; Eilers et al., 1995; Finch and Augustine, 1998; Takechi et al., 1998). The delayed component is observed after the end of PF stimulation and is mediated by $\mathrm{mGluR}$-triggered $\mathrm{Ca}^{2+}$ release via $\mathrm{IP}_{3} \mathrm{R}$ (Finch and Augustine, 1998; Takechi et al., 1998). Thus, we first stimulated PFs with 10 stimuli at $50 \mathrm{~Hz}$ with a minimal intensity sufficient for inducing a substantial delayed component of the $\mathrm{Ca}^{2+}$ transient. A small initial $\mathrm{Ca}^{2+}$ transient and a substantial delayed $\mathrm{Ca}^{2+}$ transient were observed (Fig. $3 \mathrm{~A}$, middle traces), indicating that the number of activated PFs was insufficient for AMPAR-triggered $\mathrm{Ca}^{2+}$ influx (Eilers et al., 1995) but sufficient for mGluR-triggered $\mathrm{Ca}^{2+}$ release (Finch and Augustine, 1998; Takechi et al., 1998). Small GFP-PHD responses were observed simultaneously with the delayed $\mathrm{Ca}^{2+}$ transients (Fig. 3 $A$, top traces). 
To investigate the involvement of AMPAR-triggered $\mathrm{Ca}^{2+}$ influx in $\mathrm{PF}$-induced $\mathrm{IP}_{3}$ production, we then increased the stimulus intensity to stimulate a larger number of PFs, enhancing AMPAR-triggered $\mathrm{Ca}^{2+}$ influx. EPSC showed an increased amplitude by a factor of $\sim 2.7$ and a prolonged decay time course (Fig. 3A, bottom traces, $B$, left graph). There was a substantial increase in the $\mathrm{Ca}^{2+}$ concentration, the onset of which coincided with the EPSC (Fig. $3 A$, middle traces, $B$, middle graph). There was also a significant delayed component in the $\mathrm{Ca}^{2+}$ signal attributable to $\mathrm{Ca}^{2+}$ release, although an apparent plateau phase was reached because of the saturation of X-rhod-1 with $\mathrm{Ca}^{2+}$ (Fig. 3A, middle traces). $\mathrm{IP}_{3}$ production was considerably increased (Fig. $3 A$, top traces, $B$, right graph) when $\mathrm{Ca}^{2+}$ transient showed a substantial AMPAR-triggered $\mathrm{Ca}^{2+}$ influx.

\section{PF-induced $\mathrm{IP}_{3}$ production and $\mathrm{Ca}^{2+}$ transient were mediated cooperatively by mGluR and AMPAR}

There are two possibilities for the cause of enhanced $\mathrm{IP}_{3}$ production with the increased intensity of PF stimulation as shown in Figure 3. It may be simply attributable to an increased glutamate concentration at the synaptic site inducing an enhanced activation of mGluR. Alternatively, AMPAR-mediated $\mathrm{Ca}^{2+}$ influx may have induced $\mathrm{IP}_{3}$ production, as has been shown previously (Okubo et al., 2001). To test these possibilities, we studied the contribution of $\mathrm{mGluR}$ and AMPAR to $\mathrm{PF}$-induced $\mathrm{IP}_{3}$ production using specific antagonists for these receptors.

We first studied the effect of a group I mGluR antagonist, (4-CPG, $1 \mathrm{mM}$ ). The antagonist reduced $\mathrm{PF}$-induced $\mathrm{IP}_{3}$ production to a level that could not induce a significant GFP-PHD translocation (Fig. $4 A$, top traces) and blocked the later component of PF-induced $\mathrm{Ca}^{2+}$ transient (Fig. $4 A$, middle traces). The residual $\mathrm{Ca}^{2+}$ transient should be attributable mostly to AMPARtriggered $\mathrm{Ca}^{2+}$ influx via the voltage-gated $\mathrm{Ca}^{2+}$ channel. Thus, AMPAR-triggered $\mathrm{Ca}^{2+}$ influx itself could not induce $\mathrm{IP}_{3}$ production that could induce a significant GFP-PHD translocation under this condition (10 stimuli at $50 \mathrm{~Hz}$ ) (also see Fig. 5). The peak amplitude of EPSC was unaffected by 4-CPG, although the decay phase of EPSC was partially decreased (Fig. $4 A$, bottom traces). This 4-CPG-sensitive EPSC component presumably corresponds to the current via the TRPC1 channel triggered by the activation of group I mGluRs (mGluR-EPSC) in Purkinje cells (Tempia et al., 1998; Kim et al., 2003). Because it was reported that mGluR-EPSC could mediate $\mathrm{Ca}^{2+}$ influx (Tempia et al., 2001), it is possible that the 4 -CPG-sensitive $\mathrm{Ca}^{2+}$ component includes not only $\mathrm{Ca}^{2+}$ release from the intracellular store but also $\mathrm{Ca}^{2+}$ influx mediated by mGluR-EPSC.

We then studied the effect of an AMPAR antagonist (NBQX, $10 \mu \mathrm{M}$ ). Most of the EPSC was blocked by NBQX (Fig. 4 A, bottom traces). The residual EPSC component is probably mediated by mGluR-EPSC. Quite unexpectedly, NBQX blocked not only the first component but also the later component of the $\mathrm{Ca}^{2+}$ transient (Fig. $4 A$, middle traces). The $\mathrm{Ca}^{2+}$ release via $\mathrm{IP}_{3} \mathrm{R}$ from the intracellular store and perhaps $\mathrm{Ca}^{2+}$ influx mediated by mGluR-EPSC seems to underlie the residual $\mathrm{Ca}^{2+}$ transient. A remarkable feature of the effect of NBQX was that it significantly reduced the PF-induced $\mathrm{IP}_{3}$ production (Fig. $4 A$, top traces). This result indicates that the activation of $\mathrm{mGluR}$ is not sufficient for but the coactivation of mGluR and AMPAR is necessary for the full $\mathrm{IP}_{3}$ production on $\mathrm{PF}$ stimulation, although the activation of AMPAR alone cannot induce a significant amount of $\mathrm{IP}_{3}$ production. Indeed, the sum of the $\mathrm{IP}_{3}$ transients in the presence of either 4-CPG or NBQX was significantly smaller than the $\mathrm{IP}_{3}$ transient in the absence of antagonists (Fig. 4B) (also see Fig. 5).
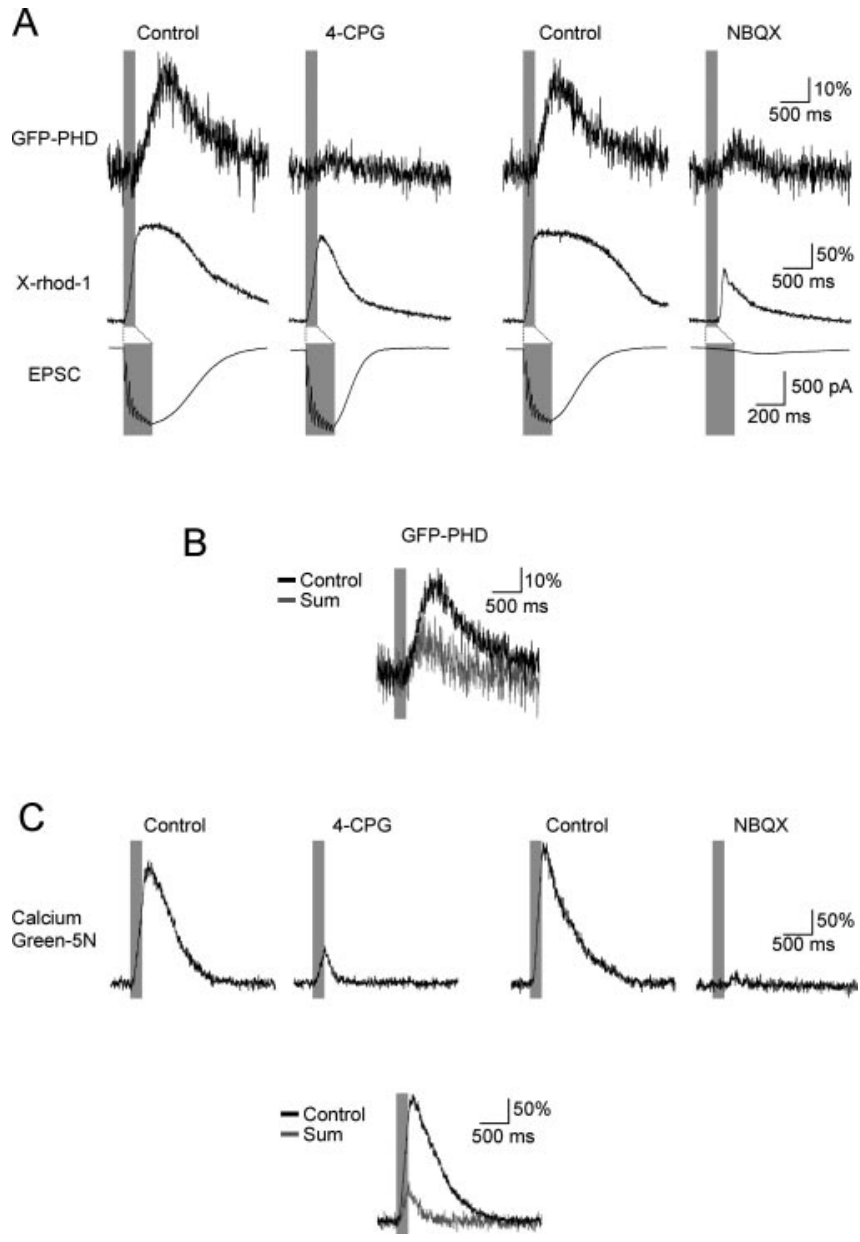

Figure 4. Effect of glutamate receptor antagonists on PF-induced response. $A$, Effects of the group I mGluR antagonist 4-CPG (1 mM) and AMPAR antagonist NBQX (10 $\mu \mathrm{m})$. Averaged traces (7 runs from 7 cells for the 4-CPG experiment, 6 runs from 6 cells for the NBQX experiment) of $I_{3}$ production (top traces), $\mathrm{Ca}^{2+}$ transient (middle traces), and EPSC (bottom traces) during PF stimulation (10 stimuli at $50 \mathrm{~Hz}$, indicated by the gray bar). After the measurement under the control condition, 4-CPG or NBQX was perfused for 4-7 min, and then the measurement was performed at the same location. $B$, Cooperativity in $\mathrm{IP}_{3}$ production during $\mathrm{PF}$ stimulation. The linear sum of the averaged traces in the presence of 4-CPG or NBQX shown in $A$ is compared with an averaged trace under the control condition (13 runs from 13 cells). C, Cooperativity in Ca ${ }^{2+}$ transient detected using Calcium Green-5N. Averaged time courses ( 9 runs from 9 cells for the 4-CPG experiment, 8 runs from 8 cells for the NBQX experiment) of the $\mathrm{Ca}^{2+}$ transient on PF stimulation are shown (top traces). The linear sum of averaged traces in the presence of 4-CPG or NBQX is significantly smaller than that of the averaged trace under the control condition (bottom trace).

Taken together, the effects of 4-CPG and NBQX on the PFinduced $\mathrm{IP}_{3}$ production indicate that $\mathrm{PF}$-induced $\mathrm{IP}_{3}$ production is dependent on the simultaneous activation of group I mGluR and AMPAR. Thus, there is a robust cross talk between mGluR and iGluR for $\mathrm{IP}_{3}$ production at the $\mathrm{PF} \rightarrow$ Purkinje cell synapse.

We then examined how the cross talk between mGluR and AMPAR affects the PF-induced $\mathrm{Ca}^{2+}$ transients. Because the $\mathrm{Ca}^{2+}$ transients measured by X-rhod-1 $\left(K_{\mathrm{d}}, 700 \mathrm{nM}\right)$ show the sign of saturation (Fig. 4A, Control), we imaged the PF-induced $\mathrm{Ca}^{2+}$ response using a low-affinity $\mathrm{Ca}^{2+}$ indicator, Calcium Green-5N ( $\left.K_{\mathrm{d}}, 14 \mu \mathrm{M}\right)$ (Fig. 4C). Calcium Green-5N was applied through the patch pipette to Purkinje cells and was excited at 810 $\mathrm{nm}$. In the presence of 4-CPG, a greater part of the $\mathrm{Ca}^{2+}$ transient was blocked, leaving the small response coinciding with PF stimulation. NBQX almost completely blocked the PF-induced $\mathrm{Ca}^{2+}$ 
response. The $\mathrm{Ca}^{2+}$ transient under the control condition was significantly larger than the sum of the $\mathrm{Ca}^{2+}$ transients in the presence of either antagonist.

\section{Dependence on the number of PF inputs of the cooperative $\mathrm{IP}_{3}$ production}

To study how the cooperativity of mGluR and AMPAR in $\mathrm{IP}_{3}$ signaling depends on the intensity of synaptic inputs, we examined the magnitude of $\mathrm{IP}_{3}$ production on the number of PF stimulations while maintaining the frequency at $50 \mathrm{~Hz}$. In the absence of antagonists, trains of as few as three pulses induced detectable $\mathrm{IP}_{3}$ production, and the size of the response showed a steep dependence on the number of pulses between 3 and 20 pulses (Fig. $5 A, B$, black circles). The amplitude and the duration of PFinduced $\mathrm{IP}_{3}$ production saturated at 20 pulses. When mGluR was blocked in the presence of $1 \mathrm{~mm} 4-\mathrm{CPG}$, no significant $\mathrm{IP}_{3}$ production was observed in response to 10 or fewer pulses, showing that the activation of AMPAR alone is not sufficient for $\mathrm{IP}_{3}$ production in this range of PF inputs (Fig. 5A) (also see Fig. 4A). However, significant $\mathrm{IP}_{3}$ production was observed on 20 and 40 pulses of $\mathrm{PF}$ inputs, although the magnitude was approximately half that of control experiments (Fig. 5A,B, red circles). Thus, strong AMPAR activation could induce $\mathrm{IP}_{3}$ production in Purkinje cells, in accordance with our previous report (Okubo et al., 2001). When AMPAR was blocked by $10 \mu \mathrm{M}$ NBQX, the amplitude of $\mathrm{PF}$-induced $\mathrm{IP}_{3}$ production increased with the number of pulses more than 3 (Fig. 5A, $B$, blue circles). The mGluR-triggered $\mathrm{IP}_{3}$ production showed a less steep dependence on the number of pulses than the AMPAR-mediated $\mathrm{IP}_{3}$ production. The sum of the $\mathrm{IP}_{3}$ transients in the presence of either 4-CPG or NBQX was significantly smaller than the $\mathrm{IP}_{3}$ transient in the absence of antagonists at 5 or 10 pluses, but the two values were not significantly different at greater number of pulses (Fig. $5 C$ ). Thus, the cooperativity of mGluR and AMPAR in $\mathrm{IP}_{3}$ signaling is dependent on the number of pulses and is prominent in the window of 5-10 pluses at $50 \mathrm{~Hz}$, which is within the physiological firing patterns of PFs (Merrill et al., 1978; Chadderton et al., 2004).

\section{PF-induced $\mathrm{IP}_{3}$ production required both G-protein} activation and an increase in intracellular $\mathrm{Ca}^{2+}$ concentration Having clarified the cross talk between mGluR and AMPAR in $\mathrm{IP}_{3}$ production, we then examined the intracellular mechanisms involved in the cross talk. Because mGluR is one of the G-protein-coupled receptors (Masu et al., 1991; Aramori and Nakanishi, 1992), we investigated the involvement of the G-protein in PF-induced $\mathrm{IP}_{3}$ production using GDP- $\beta \mathrm{S}$ to inhibit G-protein activity. GDP- $\beta S$ ( $2 \mathrm{~mm}$ ) was introduced into the cytoplasm through the patch pipette. In the presence of GDP- $\beta$ S, PF-mediated $\mathrm{IP}_{3}$ production was almost completely inhibited (Fig. 6, left traces). The PF-induced $\mathrm{Ca}^{2+}$ transients in the presence of GDP- $\beta$ S were similar to those in the presence of $4-\mathrm{CPG}$ (Fig. 4A, middle traces), showing that the AMPAR-dependent $\mathrm{Ca}^{2+}$ transient is normally activated in the presence of GDP- $\beta$ S. This result shows that the signaling pathway via the G-protein is critical for the cross talk between mGluR and AMPAR in $\mathrm{IP}_{3}$ production.

Next, we evaluated the signaling event triggered by the activation of AMPAR. In Purkinje cells, the activation of AMPAR is followed by depolarization, triggering $\mathrm{Ca}^{2+}$ influx via the P-type voltage-gated $\mathrm{Ca}^{2+}$ channel (Gruol et al., 1996). Thus, there is a possibility that the AMPAR-triggered $\mathrm{Ca}^{2+}$ influx enhances PFinduced $\mathrm{IP}_{3}$ production when mGluR is activated. To evaluate the involvement of $\mathrm{Ca}^{2+}$, we applied BAPTA through the patch

\section{A}

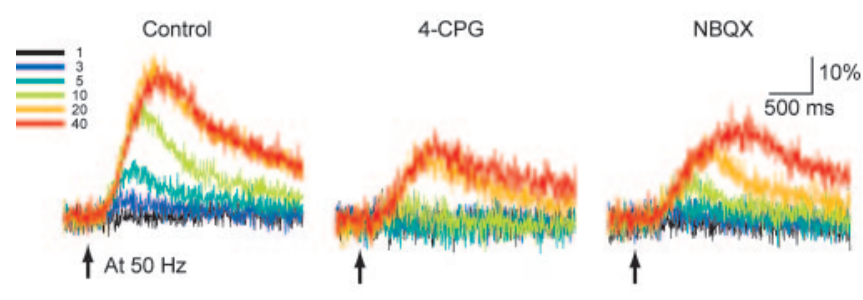

C
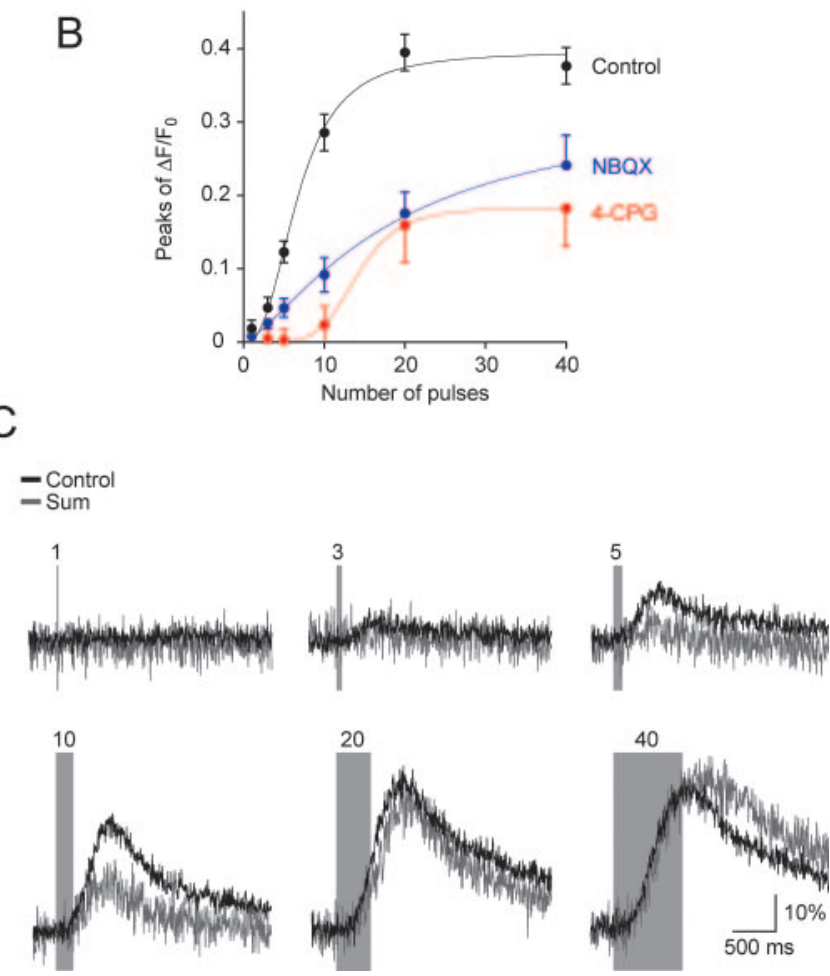

Figure 5. Dependence of cooperativity in $\mathbb{P}_{3}$ production on the number of $\mathrm{PF}$ inputs. $A$, $\mathrm{PF}$-induced $I \mathrm{P}_{3}$ production was measured by varying the number of stimuli $(1,3,5,10,20$, and 40 stimuli) at $50 \mathrm{~Hz}$ in the absence and the presence of either 4-CPG (1 mM) or NBQX $(10 \mu \mathrm{M})$. Traces are the averaged time courses of $\Delta F / F_{0}$ within the cytoplasm on PF stimulation. The onset of PF stimulation is indicated by the arrow. $B$, Peak values of $\Delta F / F_{0}$ (measured during 2.5 sec from the onset of PF stimulation) are plotted against the number of stimuli (mean \pm SEM; $n=9-11)$. Data points were fitted using Hill's equation. $C_{\text {, Cooperativity in }} \mathbb{P}_{3}$ production during varying numbers of $\mathrm{PF}$ stimulation. The linear sums of the averaged traces in the presence of 4-CPG or NBQX are compared with averaged traces under the control condition. PF stimulation $(1,3,5,10,20$, and 40 stimuli at $50 \mathrm{~Hz}$, from top left to bottom right) is indicated by the gray bar. Results from 11 experiments (control), 9 experiments (4-CPG), and 9 experiments (NBQX) are summarized.

pipette to buffer intracellular $\mathrm{Ca}^{2+}$ (Fig. 6, right traces). We observed no significant $\mathrm{IP}_{3}$ production in the presence of BAPTA. This observation was made possible by the direct measurement of $\mathrm{IP}_{3}$ generation and indicates that an increase in intracellular $\mathrm{Ca}^{2+}$ concentration is necessary for $\mathrm{PF}$-induced $\mathrm{IP}_{3}$ production.

These results indicate that the coincidental increase in G-protein activity and intracellular $\mathrm{Ca}^{2+}$ concentration is necessary for PF-induced $\mathrm{IP}_{3}$ production. This strongly suggests that the cross talk between mGluR and AMPAR in $\mathrm{IP}_{3}$ production is mediated through mGluR-triggered G-protein activation and AMPAR-triggered $\mathrm{Ca}^{2+}$ influx. 


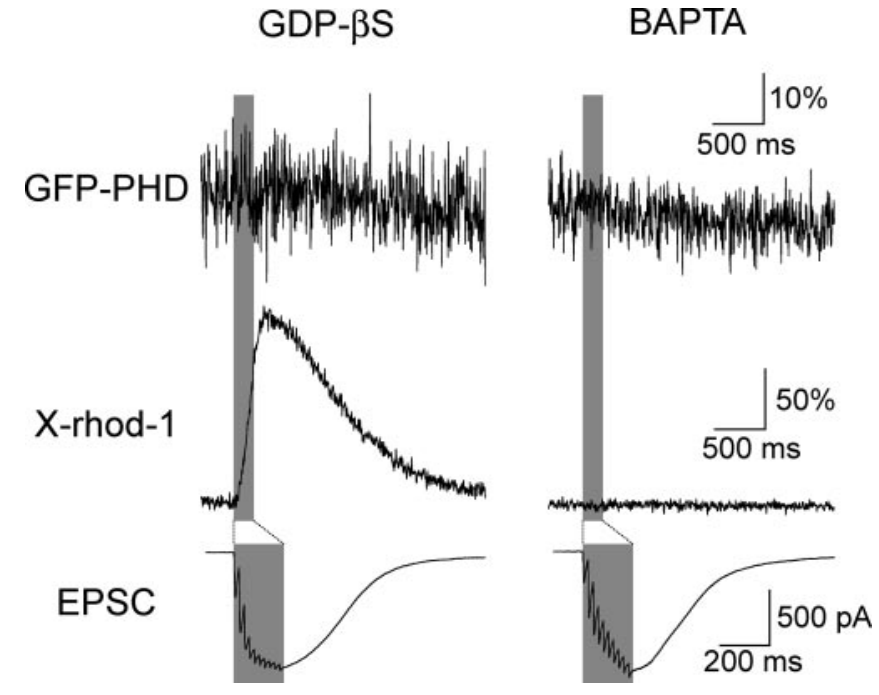

Figure 6. $\mathrm{PF}$-induced $\mathrm{IP}_{3}$ production depends on $\mathrm{G}$-protein and intracellular $\mathrm{Ca}^{2+}$. Averaged traces ( 6 runs from 5 cells for the GDP- $\beta$ S experiment, 7 runs from 6 cells for the BAPTA experiment) of $\mathrm{IP}_{3}$ production, $\mathrm{Ca}^{2+}$ transient, and EPSC during PF stimulation (10 stimuli at 50 $\mathrm{Hz}$, indicated by the gray bar) are shown. PF-induced IP ${ }_{3}$ production was completely blocked by the intracellular delivery of $2 \mathrm{~mm}$ GDP- $\beta$ S (left traces) or $20 \mathrm{~mm}$ BAPTA (right traces).

\section{Discussion}

We visualized and analyzed the PF-induced $\mathrm{IP}_{3}$ dynamics in Purkinje cells. The present study showed that PF-induced $\mathrm{IP}_{3}$ production is cooperatively mediated by mGluR and AMPAR via $\mathrm{G}$-protein activation and $\mathrm{Ca}^{2+}$ influx. The present results may shed light on the functional significance of the close distribution of mGluR and iGluR at excitatory synapses in the CNS.

\section{Candidate components that mediate the mGluR-AMPAR cross talk}

The group I mGluRs (including mGluR1) induce $\mathrm{IP}_{3}$ production through the activation of PLC- $\beta$ isozymes that are coupled to the G-protein (Masu et al., 1991; Aramori and Nakanishi, 1992). Because Purkinje cells highly express mGluR1 (Baude et al., 1993) and PLC- $\beta$ isozymes (Watanabe et al., 1998), it is likely that the $\mathrm{PF}$ input-induced $\mathrm{IP}_{3}$ production (Fig. $4 \mathrm{~B}$, top trace) is mediated by the G-protein-PLC- $\beta$ signaling pathway. In accordance with this notion, $\mathrm{PF}$-mediated $\mathrm{IP}_{3}$ production was completely blocked by the inhibition of G-protein activity by GDP- $\beta$ S (Fig. 6). Although the activity of PLC- $\beta$ is primarily regulated by the G-protein (Rhee and Bae, 1997; Rebecchi and Pentyala, 2000), the PLC- $\beta$ activity is enhanced by an increase in intracellular $\mathrm{Ca}^{2+}$ concentration (Taylor et al., 1991; Hirose et al., 1999). Indeed, $\mathrm{IP}_{3}$ production was abrogated when the intracellular $\mathrm{Ca}^{2+}$ concentration was buffered by BAPTA (Fig. 6). Taken together, PLC- $\beta$ is the most plausible candidate protein that mediates the cross talk between mGluR-mediated G-protein activation and AMPAR-triggered $\mathrm{Ca}^{2+}$ influx, although saturation of $\mathrm{IP}_{3}-$ metabolizing enzymes and/or $\mathrm{IP}_{3}$-binding proteins may partially explain the supralinear increase in $\mathrm{IP}_{3}$ concentration.

\section{Possible physiological roles of the mGluR-AMPAR cross talk} $\mathrm{PF} \rightarrow$ Purkinje cell synapses show synaptic plasticity, such as long-term depression (LTD), which requires the concomitant activation of PF and climbing fiber (CF) synapses, and may underlie certain forms of motor learning (Ito, 2001). It was reported that, at the $\mathrm{PF} \rightarrow$ Purkinje cell synapse, the simultaneous activation of AMPAR and mGluR is necessary for the induction of LTD
(Kano and Kato, 1988; Linden et al., 1991; Hartell, 1994; Hemart et al., 1995). Indeed, LTD is absent in mGluR1-deficient mice (Aiba et al., 1994; Conquet et al., 1994). However, the role of AMPAR remains unclear. The present results indicate that AMPAR at the PF synapses cooperates with mGluR to activate PLC- $\beta$, which is involved in the induction of LTD (Miyata et al., 2001). This cooperative activation of PLC- $\beta$ may be the reason why the simultaneous activation of AMPAR and mGluR at PF synapses is necessary for the induction of LTD.

It was reported that PF inputs in combination with a CFtriggered $\mathrm{Ca}^{2+}$ influx, the stimulus used for LTD induction, induce a supralinear increase in $\mathrm{Ca}^{2+}$ release from the intracellular store within spines (Wang et al., 2000). The supralinear $\mathrm{Ca}^{2+}$ release probably involves the cooperative activation of $I_{3} R$, which requires both $\mathrm{IP}_{3}$ and $\mathrm{Ca}^{2+}$ for full activation (Iino, 1990; Bezprozvanny et al., 1991). However, possible cooperative production of $\mathrm{IP}_{3}$ by simultaneous inputs from PFs and a CF may also contribute to the generation of supralinear $\mathrm{Ca}^{2+}$ release. Future development of a technique that allows the imaging of $\mathrm{IP}_{3}$ dynamics within spines may clarify this issue.

The activation of PLC enzymes produces not only $\mathrm{IP}_{3}$ but also diacylglycerol, which is a precursor of endocannabinoids (Stella et al., 1997) as well as an activator of PKC. Endocannabinoids are retrograde signaling molecules that modulate the release rate of neurotransmitters in many brain regions and are produced on two distinct signals, an increase in $\mathrm{Ca}^{2+}$ concentration (Di Marzo et al., 1994; Stella et al., 1997) and G-protein activation via group I mGluR (Maejima et al., 2001). The present results, therefore, suggest that mGluR and AMPAR may cooperatively mediate the production of endocannabinoids at PF synapses. In general agreement with this notion, mGluR activation and depolarization-induced $\mathrm{Ca}^{2+}$ influx cooperatively generated endocannabinoids in cultured hippocampal neurons (Ohno-Shosaku et al., 2002).

In summary, the functional interaction between mGluR and iGluR was identified in $\mathrm{PF} \rightarrow$ Purkinje cell synapses. $\mathrm{IP}_{3}$ production was cooperatively induced by the activation of $\mathrm{mGluR}$ and iGluR, and the molecular coincidence detector is most likely PLC- $\beta$. This cooperation between mGluR and iGluR may play important roles in the regulation of various synaptic functions.

\section{References}

Abe T, Sugihara H, Nawa H, Shigemoto R, Mizuno N, Nakanishi S (1992) Molecular characterization of a novel metabotropic glutamate receptor mGluR5 coupled to inositol phosphate/ $\mathrm{Ca}^{2+}$ signal transduction. J Biol Chem 267:13361-13368.

Aiba A, Kano M, Chen C, Stanton ME, Fox GD, Herrup K, Zwingman TA, Tonegawa S (1994) Deficient cerebellar long-term depression and impaired motor learning in mGluR1 mutant mice. Cell 79:377-388.

Aramori I, Nakanishi S (1992) Signal transduction and pharmacological characteristics of a metabotropic glutamate receptor, mGluR1, in transfected CHO cells. Neuron 8:757-765.

Baude A, Nusser Z, Roberts JD, Mulvihill E, McIlhinney RA, Somogyi P (1993) The metabotropic glutamate receptor (mGluR $1 \alpha$ ) is concentrated at perisynaptic membrane of neuronal subpopulations as detected by immunogold reaction. Neuron 11:771-787.

Bezprozvanny I, Watras J, Ehrlich BE (1991) Bell-shaped calcium-response curves of Ins $(1,4,5) \mathrm{P}_{3^{-}}$and calcium-gated channels from endoplasmic reticulum of cerebellum. Nature 351:751-754.

Chadderton P, Margrie TW, Hausser M (2004) Integration of quanta in cerebellar granule cells during sensory processing. Nature 428:856-860.

Chesler M, Kaila K (1992) Modulation of $\mathrm{pH}$ by neuronal activity. Trends Neurosci 15:396-402.

Communi D, Lecocq R, Erneux C (1996) Arginine 343 and 350 are two active site residues involved in substrate binding by human type I D-myo-Inositol 1,4,5-trisphosphate 5-phosphatase. J Biol Chem 271:11676-11683. 
Conquet F, Bashir ZI, Davies CH, Daniel H, Ferraguti F, Bordi F, Franz-Bacon K, Reggiani A, Matarese V, Conde F, Collingridge GL, Crepel F (1994) Motor deficit and impairment of synaptic plasticity in mice lacking mGluR1. Nature 372:237-243.

Denk W, Svoboda K (1997) Photon upmanship: why multiphoton imaging is more than a gimmick. Neuron 18:351-357.

Denk W, Sugimori M, Llinas R (1995) Two types of calcium response limited to single spines in cerebellar Purkinje cells. Proc Natl Acad Sci USA 92:8279-8282.

Di Marzo V, Fontanna A, Cadas H, Schinelli S, Cimino G, Schwartz JC, Piomelli D (1994) Formation and inactivation of endogenous cannabinoid anandamide in central neurons. Nature 372:686-691.

Edwards FA, Konnerth A, Sakmann B, Takahashi T (1989) A thin slice preparation for patch-clamp recordings from neurons of the mammalian central nervous system. Pflügers Arch 414:600-612.

Ehrengruber MU, Lundstrom K, Schweitzer C, Heuss C, Schlesinger S, Gahwiler BH (1999) Recombinant Semliki forest virus and Sindbis virus efficiently infect neurons in hippocampal slice cultures. Proc Natl Acad Sci USA 96:7041-7046.

Eilers J, Augustine GJ, Konnerth A (1995) Subthreshold synaptic $\mathrm{Ca}^{2+}$ signalling in fine dendrites and spines of cerebellar Purkinje neurons. Nature 373:155-158.

Finch EA, Augustine GJ (1998) Local calcium signaling by inositol-1,4,5trisphosphate in Purkinje cell dendrites. Nature 396:753-756.

Gruol DL, Netzeband JG, Parsons KL (1996) $\mathrm{Ca}^{2+}$ signaling pathways linked to glutamate receptor activation in the somatic and dendritic regions of cultured cerebellar Purkinje neurons. J Neurophysiol 76:3325-3340.

Hartell NA (1994) Induction of cerebellar long-term depression requires activation of glutamate metabotropic receptors. NeuroReport 5:913-916.

Hemart N, Daniel H, Jaillard D, Crepel F (1995) Receptors and second messengers involved in long-term depression in rat cerebellar slices in vitro: a reappraisal. Eur J Neurosci 7:45-53.

Hirose K, Kadowaki S, Tanabe M, Takeshima H, Iino M (1999) Spatiotemporal dynamics of inositol 1,4,5-trisphosphate that underlies complex $\mathrm{Ca}^{2+}$ mobilization patterns. Science 284:1527-1530.

Iino M (1990) Biphasic $\mathrm{Ca}^{2+}$ dependence of inositol 1,4,5-trisphosphateinduced Ca release in smooth muscle cells of the guinea pig Taenia caeci. J Gen Physiol 95:1103-1122.

Ito M (2001) Cerebellar long-term depression: characterization, signal transduction, and functional roles. Physiol Rev 81:1143-1195.

Kakizawa S, Yamasaki M, Watanabe M, Kano M (2000) Critical period for activity-dependent synapse elimination in developing cerebellum. J Neurosci 20:4954-4961.

Kano M, Kato M (1988) Mode of induction of long-term depression at parallel fibre-Purkinje cell synapses in rabbit cerebellar cortex. Neurosci Res 5:544-556.

Kim SJ, Kim YS, Yuan JP, Petralia RS, Worley PF, Linden DJ (2003) Activation of the TRPC1 cation channel by metabotropic glutamate receptor mGluR1. Nature 426:285-291.

Kneen M, Farinas J, Li Y, Verkman AS (1998) Green fluorescent protein as a noninvasive intracellular pH indicator. Biophys J 74:1591-1599.

Laxminarayan KM, Chan BK, Tetaz T, Bird PI, Mitchell CA (1994) Characterization of a cDNA encoding the 43-kDa membrane-associated inositol-polyphosphate 5-phosphatase. J Biol Chem 269:17305-17310.

Linden DJ, Dickinson MH, Smeyne M, Connor JA (1991) A long-term depression of AMPA currents in cultured cerebellar Purkinje neurons. Neuron $7: 81-89$.
Maejima T, Hashimoto K, Yoshida T, Aiba A, Kano M (2001) Presynaptic inhibition caused by retrograde signal from metabotropic glutamate to cannabinoid receptors. Neuron 31:463-475.

Majerus PM (1992) Inositol phosphate biochemistry. Annu Rev Biochem 61:225-250.

Masu M, Tanabe Y, Tsuchida K, Shigemoto R, Nakanishi S (1991) Sequence and expression of a metabotropic glutamate receptor. Nature 349:760-765.

Merrill EG, Wall PD, Yaksh TL (1978) Properties of two unmyelinated fibre tracts of the central nervous system: lateral Lissauer tract, and parallel fibres of the cerebellum. J Physiol (Lond) 284:127-145.

Miyata M, Kim HT, Hashimoto K, Lee TK, Cho SY, Jiang H, Wu Y, Jun K, Wu D, Kano M, Shin HS (2001) Deficient long-term synaptic depression in the rostral cerebellum correlated with impaired motor learning in phospholipase C beta4 mutant mice. Eur J Neurosci 13:1945-1954.

Nemoto T, Kimura R, Ito K, Tachikawa A, Miyashita Y, Iino M, Kasai H (2001) Sequential-replenishment mechanism of exocytosis in pancreatic acini. Nat Cell Biol 3:253-258.

Nusser Z, Mulvihill E, Streit P, Somogyi P (1994) Subsynaptic segregation of metabotropic and ionotropic glutamate receptors as revealed by immunogold localization. Neuroscience 61:421-427.

Ohno-Shosaku T, Shosaku J, Tsubokawa H, Kano M (2002) Cooperative endocannabinoid production by neuronal depolarization and group I metabotropic glutamate receptor activation. Eur J Neurosci 15:953-961.

Okubo Y, Kakizawa S, Hirose K, Iino M (2001) Visualization of $\mathrm{IP}_{3}$ dynamics reveals a novel AMPA receptor-triggered $\mathrm{IP}_{3}$ production pathway mediated by voltage-dependent $\mathrm{Ca}^{2+}$ influx in Purkinje cells. Neuron 32:113-122.

Rebecchi MJ, Pentyala SN (2000) Structure, function, and control of phosphoinositide-specific phospholipase C. Physiol Rev 80:1291-1335.

Rhee SG, Bae YS (1997) Regulation of phosphoinositide-specific phospholipase C isozymes. J Biol Chem 272:15045-15048.

Stella N, Schweitzer P, Piomelli D (1997) A second endogenous cannabinoid that modulates long-term potentiation. Nature 388:773-777.

Takahashi N, Kishimoto T, Nemoto T, Kadowaki T, Kasai H (2002) Fusion pore dynamics and insulin granule exocytosis in the pancreatic islet. Science 297:1349-1352.

Takechi H, Eilers J, Konnerth A (1998) A new class of synaptic response involving calcium release in dendritic spines. Nature 396:757-760.

Takumi Y, Matsubara A, Rinvik E, Ottersen OP (1999) The arrangement of glutamate receptors in excitatory synapses. Ann NY Acad Sci 868:474-482.

Taylor SJ, Chae HZ, Rhee SG, Exton JH (1991) Activation of the $\beta 1$ isozyme of phospholipase $\mathrm{C}$ by $\alpha$ subunits of the $\mathrm{G}_{\mathrm{q}}$ class of $\mathrm{G}$ proteins. Nature 350:516-518.

Tempia F, Concetta M, Anchisi D, Strata P (1998) Postsynaptic current mediated by metabotropic glutamate receptors in cerebellar Purkinje cells. J Neurophysiol 80:520-528.

Tempia F, Alojado ME, Strata P, Knöpfel T (2001) Characterization of the $\mathrm{mGluR}_{1}$-mediated electrical and calcium signaling in Purkinje cells of mouse cerebellar slices. J Neurophysiol 86:1389-1397.

Wang SS-H, Denk W, Hausser M (2000) Coincidence detection in single dendritic spines mediated by calcium release. Nat Neurosci 3:1266-1273.

Watanabe M, Nakamura M, Sato K, Kano M, Simon MI, Inoue Y (1998) Patterns of expression for the mRNA corresponding to the four isoforms of phospholipase $C \beta$ in mouse brain. Eur J Neurosci 10:2016-2025. 